\title{
TIME-LAPSE VIDEO STUDY OF MATING BEHAVIOR IN SAGEBRUSH CRICKETS (Cyphoderris strepitans)
}

Scott K. Sakaluk

Department of Biological Sciences

Illinois State University

Normal

and

W. Andrew Snedden

Department of Zoology, Erindale College

University of Toronto

Mississauga, ontario

\section{Introduction}

Sagebrush crickets (Cyphoderris strepitans) are primitive acoustic insects which occur only in mountainous areas of Wyoming and Colorado (Morris and Gwynne 1978). In Grand Teton National Park, adults become sexually active in early May and matings subsequently occur over a $3-6$ week period. Each night of the breeding season, males emerge from the soil litter shortly after sunset, climb into the sagebrush and begin to sing, presumably to attract sexually receptive females. Copulation is initiated when a receptive female climbs onto the dorsum of a male, at which time he attempts to transfer a spermatophore (Dodson et al. 1983, Sakaluk et al. 1987, Morris et al. 1989).

During the time that the female is mounted on the male, she feeds on the male's metathoracic wings and ingests any hemolymph oozing from the wounds she inflicts. To deter the female from dismounting before the spermatophore has been transferred, males are equipped with an abdominal pinching organ which functions to secure the female during copulation (Morris 1979, Dodson et al. 1983). Once the spermatophore has been transferred, the male actively pulls away from the female, and he may resume calling immediately after disengagement. The bulk of the spermatophore remains attached outside the female's body, who invariably consumes it several hours after mating (present study).

A previous field study involving the mark-recapture of a large number of males showed that once a male had mated, his probability of obtaining additional copulations was 
significantly reduced (Morris et al. 1986). One explanation for this result is that non-virgin males, having lost a substantial portion of available energy reserves at mating, may be unable to sustain calling at pre-mating levels. In support of this hypothesis, electronic assays of male signaling behavior (see Kidder and Sakaluk, in press) have shown that virgin male $\underline{c}$. strepitans call for significantly longer durations than recently mated males (Sakaluk et al. 1987, Sakaluk and Snedden 1990).

Although virgin males call more and have significantly higher mating success than non-virgins, this does not necessarily prove that calling duration and mating success are causally related. In the past, we have experienced two difficulties in establishing a causal basis to this correlation: 1) matings are rarely observed in the field, and we have of necessity relied on wing wounding as an indicator of male mating success (Morris et al. 1989) and 2) we have been unable to demonstrate phonotaxis of females to conspecific song as broadcast either through speakers placed in the field (Sakaluk and Snedden, unpubl. data) or in the laboratory (Morris et al. 1989). To at least partially circumvent these difficulties, we employed time-lapse video photography of mating interactions staged at the UW-NPS Research Station during the 1989 breeding season. The objective of these studies was to determine how mating status, calling time and body size contribute to male mating success, either through their effect on male competitive ability and/or their effect on male attractiveness to females.

\section{Methods}

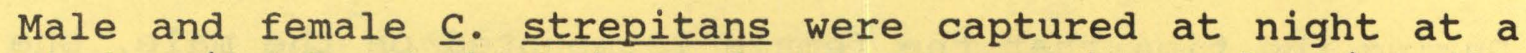
study site located on top of an escarpment overlooking the Snake River at Dead Man's Bar in Grand Teton National Park. Perching locations of males were found by orienting to the acoustic signals produced by individual males and then searching the sagebrush with the aid of a headlamp. Because females are mute, they were found largely through chance encounters. Crickets were transported back to the research station where they were housed in plastic vials provisioned every other day with a slice of apple.

Triadic mating interactions were staged in a plexiglass arena and recorded using a time-lapse video recorder (Panasonic AG-6050) and a camera equipped with a macro lens (Panasonic WV-3250/8AF). Each triad consisted of a virgin male (as evidenced by a lack of wing wounding), a non-virgin male (as evidenced by wing wounding) and a female of unknown mating 
status. All crickets were weighed prior to introduction into the arena. Each night of the study, a single triad was established at approximately 2000 hours at which time recording commenced. The video recorder was set to the $12-\mathrm{H}$ recording option; on this time mode, a single frame is recorded every 0.1 seconds. In total, we video-taped 20 triadic interactions over 20 nights of which 15 resulted in matings. When a mating occurred, the participants involved in the interaction were never used again; thus, we obtained behavioral data on a total of 45 individuals involved in mating interactions.

Upon review of video-tape recordings of mating interactions, we recorded: 1) the number of mating opportunities for each male (as indicated by wing feeding behavior of the female and/or clamping of the female's abdomen by the male's abdominal pinching organ), 2) the frequency and duration of copulations, 3) the nature of male-male interactions and 4) the frequency and duration of spermatophore feeding by the female.

\section{Results}

\section{Mating Frequency}

In the 15 interactions leading to copulation, the male to first mate with the female was designated the 'successful' male while the other male was designated 'unsuccessful'. Initial copulations occurred, on the average, $355.6 \pm 210.8$ minutes (mean \pm 1 SD) after the introduction of experimental individuals (range $=24-643 \mathrm{~min}$ ) and were, on the average, $245.5 \pm 84.4$ seconds long (range $=120-385 \mathrm{sec}$ ). In five of the 15 interactions, two matings occurred during the recording interval; three of the second matings involved the successful male and two involved the unsuccessful male. Second matings by successful males occurred 107, 196 and 245 minutes, respectively, subsequent to the first.

\section{Correlates of Male Mating Success}

i) Calling Duration: Pre-copulatory calling durations of successful males were significantly longer than those of unsuccessful males (Table 1). In 10 interactions, the successful male was the last to call before the copulation occurred versus two interactions in which the unsuccessful male was the last to call $\left(\mathrm{X}_{\text {yates }}^{2}=4.08, \underline{\mathrm{P}}<0.05\right)$. 
Table 1. Pre-copulatory calling durations of mated and unmated male $\underline{c}$. strepitans in triadic interactions. Means are significantly different at $\underline{\mathrm{P}}<0.025$ (paired t-test, one-tailed, $t=2.19$ ).

\begin{tabular}{lcccr}
\hline \hline & $\mathrm{N}$ & Mean (min) & SD & Range \\
Mated & 15 & 189.3 & 166.2 & $0-433$ \\
Unmated & 15 & 102.3 & 104.8 & $3-302$ \\
\hline
\end{tabular}


Calling did not always immediately precede a successful copulation. In nine cases, the successful male was calling at the time the mating occurred, but on five occasions the successful male had ceased calling for 1-47 minutes prior to copulation. On one occasion, the successful male did not call at all prior to copulation, but was standing immediately adjacent to a calling (unsuccessful) male at the time the female mounted him.

ii) Mating opportunities: Successful males had significantly more mating opportunities than unsuccessful males, both before copulation $(2.1 \pm 2.0$ vs $0.5 \pm 1.0$, wilcoxon paired sample test, $\underline{P}<0.01$ ) and over the entire $12-\mathrm{h}$ recording interval $(3.5 \pm 3.5$ vs $1.0 \pm 1.4, \underline{P}<0.025)$

iii) Mating status: Nine of 15 successful males were originally virgins, while the remaining six were originally non-virgins; although suggestive, this difference is not statistically significant $\left(x^{2}\right.$ yates $\left.=0.27, \underline{p}>0.05\right)$. Calling durations of virgin males were significantly longer than those of non-virgins (Table 2). Although the number of mating opportunities experienced by virgins and non-virgins prior to copulation did not differ $(1.9 \pm 2.3$ vs $0.7 \pm 0.8,0.1>\underline{p}>$ $0.05)$, virgins had significantly more mating opportunities than non-virgins over the entire 12 -h recording period $(3.5 \pm$ 3.7 vs $1.0 \pm 1.1, \underline{\mathrm{P}}<0.025)$.

iv) Male Body Size: There was no signicant difference in the wet mass of successful and unsuccesssful males, nor in the mass of virgin and non-virgin males.

Male-Male competition

No overt aggression was ever observed between males. Frequently, however, one male would mount the other and engage in wing feeding for a variable length of time. We observed 11 such homosexual mountings distributed over six interactions. In such cases, the mounted male would expose the underlying metathoracic wings and attempt genitalic contact in much the same manner as if he had been mounted by a female. Homosexual mountings were of variable duration and invariably terminated with the mounted male pulling away.

Female Behavior

Females frequently mounted males and engaged in wing feeding without receiving the spermatophore. Such 'opportunistic feedings' occurred in $10 / 15$ interactions and at a variable frequency within interactions (range $=1-11$ ). 
Table 2. Pre-copulatory calling durations of virgin and non-virgin male $\underline{c}$. strepitans in triadic interactions. Means are significantly different at $\underline{\mathrm{P}}<0.05$ (paired $t$-test, one-tailed, $t=1.94$ ).

\begin{tabular}{lcccc}
\hline \hline & N & Mean (min) & SD & Range \\
\hline Virgin & 15 & 185.4 & 169.4 & $6-433$ \\
Non-Virgin & 15 & 106.1 & 103.0 & $0-302$ \\
\hline
\end{tabular}


With one exception in which the spermatophore was dislodged against a wall of the chamber, females always consumed the spermatophore after mating; spermatophore consumption commenced, on the average, $144.9 \pm 143.8$ minutes after the initial copulation ( $n=14$, range $=3-512 \mathrm{~min})$.

\section{Conclusions}

\section{Calling Duration and Male Mating Success}

This study demonstrates that male calling duration and subsequent mating success of males are directly associated. There are at least two hypotheses to account for this association. The 'incidental effect' hypothesis suggests that female responsiveness is unaffected by male calling behavior. Instead, successful males are more sexually motivated than unsuccessful males, and consequently call more and engage in more mating attempts. In this scenario, the correlation between calling duration and mating success would be entirely spurious, since males that engaged in more frequent mating attempts (and incidentally called for longer durations) would experience a higher mating success. The 'functional' hypothesis suggests that females respond to the acoustic signals of males. In this scenario, calling serves to attract females and/or to induce them to mount, such that males which called for longer durations would obtain more matings, either through a greater passive attraction of females and/or an active female preference.

The 'incidental-effect' hypothesis is supported by two observations: 1) there is no evidence of female phonotaxis in this species and 2) in this study, successful males experienced significantly more mating opportunities than unsuccessful males prior to copulation. Nonetheless, the hypothesis is weakened by the observation that unsuccessful males called prior to copulations in all interactions, and often permitted females to feed opportunistically; this suggests that unsuccessful males were sufficiently motivated to mate.

The 'functional' hypothesis also is supported by two observations: 1) successful males were the last to call prior to copulation more often than expected on the basis of chance and 2) calling immediately preceded copulation in nine of 15 interactions. The hypothesis is weakened by our inability to demonstrate female phonotaxis to the calling songs of males. 
As we have argued previously, however, elicitation of a female response may require an extended period of auditory stimulation that exceeds the short response times expected of females in standard phonotaxis bioassays (Sakaluk and snedden 1990). In support of this possibility, males of the present study were often obliged to call for several hours before copulation occurred.

Male Competition and Female Choice

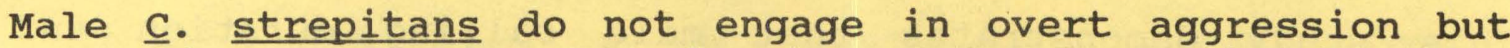
appear instead to compete primarily through acoustic signaling behavior. Homosexual mounting and opportunistic feeding by males may also be a subtle form of intrasexual competition. By feeding on another male, a male obtains not only a source of nutriment but may render a competitor a less effective signaler. At present, however, we do not know the frequency at which such behavior occurs in nature assuming that it occurs at all. Variation in male mating success may also be influenced by an active female preference for longer-calling males. One way to distinguish this possibility from differential passive attraction of females, is to examine those interactions in which both males were calling at the time the copulation occurred. We would predict that males which called the longest prior to the female's decision to mate would achieve significantly more matings. Unfortunately, we have insufficient data with which to test this prediction. Another potential avenue of female choice involves the removal of spermatophores subsequent to mating. Assuming that some time is required for the spermatophore to be evacuated of sperm, then premature spermatophore removal could be used as a means of 'cryptic' female choice (Thornhill 1983) while females continued to enjoy the benefits derived through courtship feeding. In this regard, we note that females occasionally began feeding on the spermatophore within as little as several minutes of copulation.

\section{Literature cited}

Dodson, G.N., G.K. Morris and D.T. Gwynne. 1983. Mating behavior of the primitive orthopteran genus Cyphoderris (Haglidae). In: orthopteran Mating systems: Sexual Competition in a Diverse Group of Insects, ed. by D.T. Gwynne and G.K. Morris. pp. 305-318. Westview Press, Boulder, Co. 
Kidder, G.W. III. and S.K. Sakaluk. in press. A simple and inexpensive electronic device for automatic recording and analysis of insect acoustical activity. Fla. Ent.

Morris, G.K. 1979. Mating systems, paternal investment and aggressive behavior of acoustic orthoptera. Fla. Ent. 62: 9-17.

Morris, G.K. and D.T. Gwynne. 1978. Geographical distribution and biological observations of Cyphoderris (Orthoptera: Haglidae) with a description of a new species. Psyche 85: 147-167.

Morris, G.K., D.E. Klimas, D.T. Gwynne and S.K. Sakaluk. 1989. Virgin male mating advantage in a primitive acoustic insect (Orthoptera: Haglidae). J. Insect Behav. 2: 173-185.

Sakaluk, S.K., G.K. Morris and W.A. Snedden. 1987. Mating and its effect on acoustic signalling behaviour in a primitive orthopteran, Cyphoderris strepitans (Haglidae): the cost of feeding females. Behav. Ecol. Sociobiol. 21: 173-178.

Sakaluk, S.K. and W.A. Snedden. 1990. Nightly calling durations of male sagebrush crickets, Cyphoderris strepitans: size, mating and seasonal effects. Oikos (in press).

Thornhill, R. 1983. Cryptic female choice and its implications in the scorpionfly Harpobittacus nigriceps. Am. Nat. 122: $765-788$. 